\title{
User-centered shape grammars for housing transformations: towards post-handover grammars
}

\section{SIGRADI2018 TECHNOPOLITICAS \\ xxii congresso da sociedade iberoamericana de gráfica digital 22th conference of the iberoamerican society of digital graphics 07|08|09|novembro|2018 iau usp | são carlos | sp br}

\author{
Sara Eloy \\ ISCTE-Instituto Universitário de Lisboa (ISTAR-IUL) | Portugal | sara.eloy@iscte-iul.pt \\ Maria Ângela Dias \\ Universidade Federal do Rio de Janeiro | Brazil | magedias@gmail.com
}

Pieter E. Vermaas

Delft university of Technology | The Netherlands | p.e.vermaas@tudelft.nl

\begin{abstract}
This paper presents a post-handover shape grammar for introducing inhabitants wishes in the transformation of individual houses of the Malagueira housing complex by Álvaro Siza Vieira in Évora, Portugal. The presented research includes a case study developed in the context of the workshop Gramática da Forma em estudos de habitação - análise, geração e customização at the Universidade Federal do Rio de Janeiro, Brazil. In this paper we present the first developments of the Malagueira transformation grammar, including corpus of analysis, shape rules, and derivations, and we discuss the opportunities that shape grammar brings to user-centered design.
\end{abstract}

Keywords: Housing; Participatory design; Shape grammar; Transformation; Inhabitants.

\section{INTRODUCTION}

Architects have been since decades researching possibilities for creating diversified designs that satisfy the needs and aspirations of users. In housing design several strategies have been developed to realize this goal of user-centeredness, as including inhabitants in the designing as in participatory design, and as developing designs that give several layout alternatives for inhabitants to choose from. The main aim of the research described here is to explore how shape grammars can strengthen these existing strategies. It will be explored how shape grammars can incorporate inhabitants' wishes in a design tool for customizing their houses such that it complies with their wishes and styles, while simultaneously encoding architectural knowledge regarding style and construction regulations. In this research we moreover focus on customizations by inhabitants of existing housing, that is, we do not develop shape grammars that can be used for customization during the architectural design phase of housing but shape grammars that can deliver such customization after the architectural handover of housings.

The research described here is the result of a workshop "Gramática da Forma em estudos de habitação - análise, geração e customização" on shape grammars, held in Rio de Janeiro, Brazil, in July 2017, with the participation of professors and graduate students of the Universidade Federal do Rio de Janeiro. The aim of this workshop was to let the participants understand and explore shape grammars. The final major assignment involved creating shape grammars, or more precisely, creating transformation grammars for capturing façade customization of housing in the Malagueira complex in Évora, Portugal, designed by Álvaro Siza Vieira. These shape grammars define what we will call post-handover shape grammars.

\section{HOUSE CUSTOMIZATION}

\section{HOUSING DIVERSITY}

For decades architects have researched possibilities for creating diversified designs that satisfy inhabitants' needs and aspirations. For Mckay (2016) "Architecture has two problems with real diversity. One is that it's visually messy. That's bad but it's not as bad as the other which is that real diversity can't be generated by architects". Seminal work by Le Corbusier in 1933 with Plan Obus for Algiers and by John Habraken in the 1960s (Habraken, 1972) on the Open Building approach were important moments when architecture made an effort to address diversity in design responding to the individuality of the inhabitants. From the 1960s onward several further pioneering projects were completed in countries like the Netherlands, the UK and Japan (Bosma, Hoogstraten, \& Vos, 2000; Kendall \& Teicher, 2000). Also, in Portugal the programme SAAL (Serviço Ambulatório de Apoio Local) that started after the 1974 revolution was a pioneer experience where architects, collaborating with inhabitants, had the main goal of facing the urgent housing needs of the low-income population of throughout the country. With only two years of activity SAAL accomplished 170 housing projects for more than 40.000 families aiming at designing with the inhabitants and not for them. In Brazil during the decades of the 1960s and 1970s policies were created to end the existence of 
slums. The first institutionalized actions were carried out in 1968, by the Communities Development Company (CODESCO), with the architect Carlos Nelson in charge of technically supporting the residents. CODESCO organized a process including inhabitants participation in the design and it made possible for families to continue together after the reallocation. Under the Brazilian financing program for housing - Programa de Crédito Solidário - Malard et al. (2006) refers to the aim to design houses following an open building approach. Although some achievements are being carried out, e.g., the project "Projeto Residencial Serra Verde. Modelo de Auto-gestão Habitacional de Interesse Social', the adoption of these models is very slow in Brazil (Malard et al., 2006).

Despite the success of these projects the fit-out of the habitable space suffered from the difficulty to balance between the dominance of the architects or the inhabitants in the design decisions. There is an identified need for customization that addresses mainly social issues by increasing identity and personalization. In this line, the participation of the inhabitants in the design process is identified to be a crucial aspect for a successful design. Hence, enabling inhabitants to have control over their future house will assure this success and will democratize architecture for all the society as a whole. Enabling citizens to participate in the design process of their environment has benefits such as citizen empowerment, increasing social capital and promoting a sense of community (Sanoff, 2008).

The above described projects share that the tools for customization are developed in the architectural design phase. These tools may allow for customization (long) after that the houses are handed over to the inhabitants but are still based on considerations from before this handover. Another possibility is to develop such tools after-handover, when the houses are already used and when inhabitants have had the opportunity to develop their needs and wishes with respect to the housing. Shape grammars may be the means to offer inhabitants such post-handover customization.

\section{SHAPE GRAMMARS FOR HOUSING DESIGN}

Shape grammars are generative design systems that, through the use of shape rules, can generate design solutions (Stiny \& Gips, 1972). An important feature of shape grammars for applications in architecture design is their possibility to generate multiple alternative design solutions for a single design brief. In this paper we focus on transformation grammars which are grammars that enable the transformation of existing designs into adjusted ones (Coimbra \& Romão, 2013; Colakoglu, 2005; Eloy \& Duarte, 2015; Knight, 1989).

Since the 1970s shape grammars have been used as rule-based design systems that can be applied for generating design solutions complying with a specific design language. A shape grammar is a set of visual/shape rules that are applied step-by-step to shapes generating alternative design solutions. For generating new designs, the rules in a shape grammar are applied recursively or repeatedly. Shape grammars are commonly divided in original grammars that enable new designs to be generated, and in analytical grammars that make it possible to understand and describe the architectural languages of existing designs (Stiny, 1980). Often analytical grammars lead to original ones when the rules derived from the existing cases are subsequently used as a starting point for new rules and new design solutions (Knight, 2015). Besides these two types, there are transformation grammars that enable a design to be transformed into another one.

Knight distinguishes four strategies for bridging from analysis to original design with shape grammars (Knight, 2015). The first one implies that from an analytical grammar, generated through existing designs, also new designs can be generated. An example of this strategy is the Malagueira grammar developed by Duarte on the work of Siza Vieira (Duarte, 2005). This grammar will be presented later in the paper.

The second strategy is very similar to the first but adds the fact that rule transformations are included. These new rules are defined based on the original rules and enable one grammar to be transformed into another grammar. The work ok Knight about de Stijl artists Vantongerloo and Glarner (Knight, 1989) is a good example of this second strategy. In this work Knight defined how rules were transformed from one period to another period of the artists' work.

The third strategy is similar to the second strategy. The difference is that transformations are done directly on the generated designs, in other words, "instead of defining rule transformations, transformation rules are defined" (Knight, 2015). This strategy can be seen in the work of Colakoglu (2005). The grammar developed by Colakoglu aims at modifying traditional Hayat houses to fit contemporary wishes. Colakogly method includes: i) the definition of shape rules from the original houses; ii) the generation of traditional houses; iii) the definition of transformation rules that apply to traditional designs and transform them into new designs.

The fourth strategy is like the previous one with the difference of not using an analytical grammar as a starting point. This strategy focuses on the design of the transformation rules. In this category of shape grammars Knight includes some that are very relevant for the present paper. An example of this strategy is the work of Eloy (Eloy \& Duarte, 2015) on the development of a transformation grammar to refurbish a specific housing type, Rabo-de-bacalhau in Lisbon, to meet the requirements of new life styles. To do so Eloy developed a grammar that only includes transformation rules that are applied to the original apartment layouts in order to generate renovated ones, adapted to the inhabitants' current wishes. Another work of this nature is the one developed by Coimbra (Coimbra \& Romão, 2013). Coimbra aims at developing a transformation grammar that can be applied to the traditional bourgeoise houses in Porto.

\section{RIO WORKSHOP}

The workshop titled Gramática da Forma em estudos de habitação - análise, geração e customização was promoted by the research group The Teaching Observation: apprehending the geometric attributes of the place's form of the Graduate Program in Architecture (PROARQ) of FAU-UFRJ. Its activities were led by 
Professor Sara Eloy, from ISCTE-IUL and coordinated by Professor Maria Angela Dias, from PROARQ / FAU-UFRJ and counted with the participation of professors and graduate students from FAU-UFRJ taking place in July 2017.

The workshop program consisted of eight modules and five face-to-face meetings. For each module a relevant bibliography was recommended that should be read in advance to prepare the sessions. The aim of the workshop was to introduce shape grammars as a methodology of analysis and architectural design, through theoretical contents, but essentially through practical experience, with a practical application in five exercises.

In the first exercise, with Froebel blocks, students should find spatial relationships, draw rules and generate variations. Along the second exercise, with the aim of exercising the application of a grammar, students were asked to study and understand the rules of the Malagueira grammar by Duarte and then generate two solutions not present in the literature. Still working with Malagueira, in the third exercise, students were encouraged to apply descriptions and composite representations. In the fourth exercise, the development from scratch of an original grammar was requested, to generate a small single-family dwelling with only one floor. The exercise mainly focused on creating rules for creating rooms and connections between them, not aiming at an architectural composition since the available time for this exercise was short. The last assignment was the longer one. In this assignment students should do one out of the following three options: i) define an analytical grammar for the apartments of the residential complex Prefeito Mendes de Moraes (commonly named as Pedregulho) by Affonso Eduardo Reidy; ii) define an analytical grammar for the Rabo-debacalhau apartments in Lisbon (Eloy, 2014); iii) define a transformation grammar for Malagueira that allows the incorporation of the customization that has been carried out informally by the inhabitants. This last exercise was developed during the week after the workshop. And the third option of this exercise is the one that leads to transformation grammars that capture customizations by inhabitants after the architectural hand-over of housings.

\section{MALAGUEIRA HOUSING COMPLEX}

\section{ORIGINAL PLAN}

In 1977 Álvaro Siza Vieira was invited by the Évora City Council to design a housing complex of 1200 dwellings. This invitation to Siza Vieira came after his participation in SAAL that followed an ideology that aimed at creating a dialogue with inhabitants for a participatory and experimental design process that responds to the individual housing needs (Rodrigues, 2015).

Siza Vieira designed an orthogonal grid forming different angles in the territory. Streets are narrow, and houses are displaced alongside them defining neighborhoods with open spaces in between for the public domain. The house unit is an attached single-family house typology, in a model that, according to Rodrigues (2015) crosses Modern with Vernacular architecture. During the design and construction process inhabitants were constantly present which implied several alterations to the original design by Siza Vieira (Rodrigues, 2015). Houses have two floors, the lower designed for the day living, including all the social areas, and the upper for the night living, with bedrooms and bathrooms. With this layout Siza Vieira developed an incremental design of the house on the second floor that could evolve during the life cycle of the family by accommodating, from the beginning, the possibility of adding extra rooms when needed. This incremental design opened the possibility for inhabitants to customize their houses during their stay there. The incremental options designed by Siza Vieira allow to increase the size of the house by adding rooms. Changes in on the composition of the facades are not included in that incremental design and are the focus of the present research.

\section{MALAGUEIRA GRAMMAR}

José Duarte (2005) developed a study on the Malagueira complex by defining a shape grammar for analyzing the houses and for generating models similar to those designed by Siza Vieira. In a first step, he identified 35 different house models and composition rules and developed an analytical grammar for them. Later he applied the developed rules to the generation of new housing design.

It is important to highlight that the Malagueira study by Duarte included the development of a computational system that, by following Malagueira principles, can generate housing solutions by translating inhabitants requirements into a design solution. The main objective of the study was to explore the possibility of massive customization of housing based on computer-aided design and production systems. According to Duarte (2005), inhabitants satisfaction is indicative of the quality of houses; therefore, a high level of personalization tends to increase the inhabitants' degree of satisfaction. The initial shape in the grammar definition is a rectangular plot and the creation of the design starts from the division of this plot and the inclusion of a patio, a traditional element in the houses of the region, and that is included in Siza Vieira's project. In a simplified summary, the application of the rules, at each stage, is based on the manipulation of rectangles and follows a scheme that is repeated in sequence: recursive division followed by a connection with a polygon and then extending rectangles. Labels are used to inform the last division defined and which is the next rectangle to be sectioned. In the article published in 2005 on the case study of Malagueira, Duarte presents the detailed rules which application go beyond the generation of the layout of the houses. Rules exist that insert walls with different thicknesses, insert the chimney, and that detail the stairs, among other actions. In this 2005 paper also the potential universe of solutions in the Malagueira grammar is presented, giving a clear idea of the extent of customization possibilities.

The research by Duarte demonstrated that the shape grammar method allows to verify the existence of combinatorial arrangements in the analyzed projects. This characteristic enables the shape grammar method to generate new projects, since it allows to obtain a variety of options from a relatively small number of pieces, such as, for instance the rooms (when defining the house) or the house blocks (when defining the urban implantation). The mass customization, using shape grammar presents itself as a less costly and more efficient design method to reach the desired diversity.

3 


\section{CURRENT SITUATION}

Almost 40 years have now passed since the first group of houses were built in Malagueira. Since then some inhabitants are still living in the original ones, others have moved out and others have moved in. Along these years inhabitants have dynamically appropriated the neighbourhood in several ways. Some have customized their houses by adding decorative elements to the façades and others have built (illegal) extensions to the houses (Figure 1, Figure 2 and Figure 3).

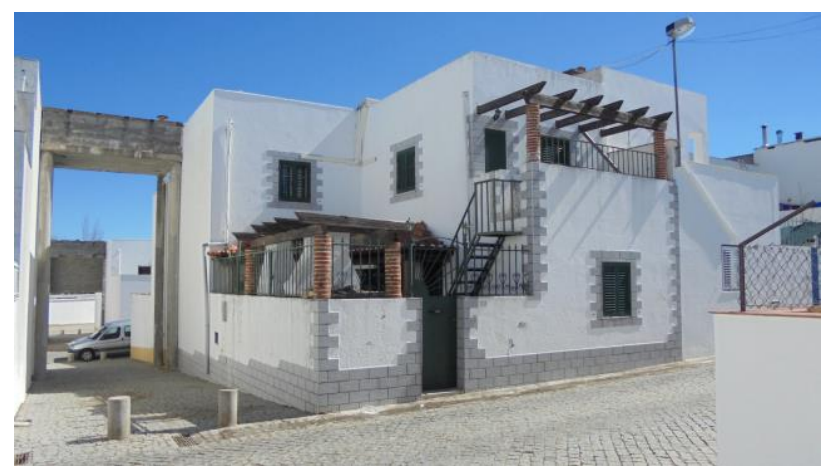

Figure 1: Malagueira current situation of housing customization (Photo: Eloy 2015)

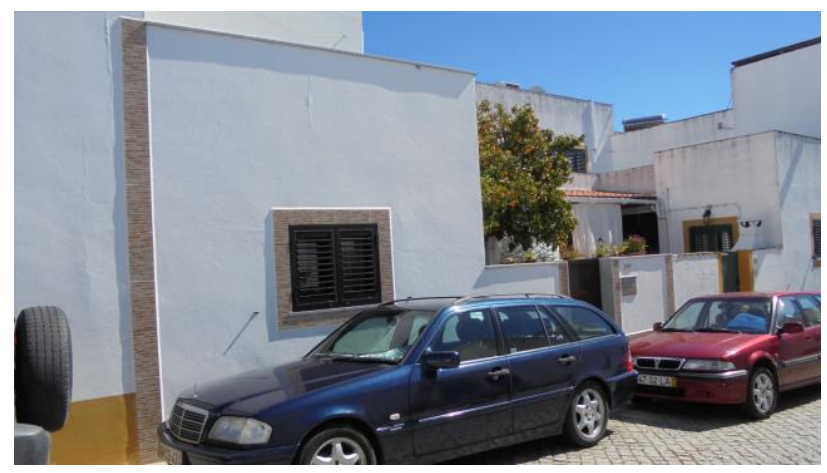

Figure 2: Malagueira current situation of housing customization (Photo: Eloy 2015)



Figure 3: Malagueira current situation of housing customization (Photo: Eloy 2015)

Gomes (2016) studied the post-occupational evaluation on the anthropological ground and the identity construction of the Malagueira project. With the postoccupational evaluation Gomes became aware that for the inhabitants the new alterations were done with an aim of being enjoyed by the neighbours and by themselves even if they did not please, or even upset, the house owners and regulators. As an example of the drive to customization Gomes says that "there were kitchens in which the objects displayed made no sense as a unified aesthetic. Instead, they found their unity in the memories of the householder". (Gomes, 2016)

This new image of Malagueira, although rich in the social perspective, also introduces questions about the intrinsic architectonic values and identity during the life span of buildings and how to maintain them without jeopardizing the individual rights of the inhabitant. These questions are fundamental to the architecture discipline and their discussion is vital to improve the success of the collaboration between the inhabitant, the final clients in housing design, and the architects.

\section{MALAGUEIRA TRANSFORMATION GRAMMAR}

In the workshop two groups of participants developed the exercise of proposing a transformation grammar for Malagueira that would respond to two important requirements: i) incorporate inhabitants wishes of customization that are identified by the current visible alterations of the exterior areas; ii) maintain the architectural quality of the housing complex designed by Siza Vieira. This exercise was an exploratory one with the aim of identifying possibilities for co-design strategies for housing. The found grammars were not developed for making them available, hence the exercise did not take in account Portuguese law that state that: i) alterations of a building from a living architect should be approved by him/her; ii) alterations to the exterior of a building should be approved by the city council. Under these laws, all currently existing alterations are illegal.

The exercise aims at focusing on the alterations performed to the composition of the facades and not to the alterations done on any other levels.

The two groups that defined a transformation grammar for Malagueira interpreted the exercise in different ways which are interesting to discuss here. The group by Daniel Athias and Marcelo Sbarra (group 1 from now on) defined a grammar that could have been used when Malagueira houses were first delivered to their original inhabitants. In this case inhabitants would have, since the beginning of their occupation, the knowledge on how to customize their house. This grammar would also enable inhabitants to transform their current houses provided they the original state of the houses as the starting point. This means that inhabitants would have a set of rules that can be applied to the original design of their houses (and not to the already altered houses).

The second group, composed by Marília Chaves Lima, defined a grammar that, besides being applied to the original designs, enables to "fix" the current situation by including rules to change the houses that, according to Lima's assessment, are now damaging the architectural quality of the housing complex by Siza Vieira. In this case, the solution was to create shape rules that are applied to the current state of the houses. This grammar would be an extension of the previous one including all current customizations not only as a corpus to analyze what was changed but also to act on it directly. One simple example of such a "fix" transformation grammar is a rule to repaint all door and gate panels that where recently painted 
white, with a different color in order to regain the original contrast between void and full (Figure 4). This second approach of transformation grammar is not the one fully described in this paper, but we will briefly explore it in Grammar Rules section.

Both strategies comply with the fourth strategy defined by Knight (2015) and follows the work of Eloy (2015) and Coimbra (2013) since transformations rules were defined without using the analytical grammar for Malagueira as given by Duarte.

In the workshop participants were asked to: i) define the corpus of work; ii) infer transformation shapes rules; iii) formalize the shape rules for transformation; iv) define the method to apply shape rules (sequence or random application of rules, use of labels, weights, among others); v) make derivations of design alternatives.



Figure 4: An example where the panel of the gate is white not creating contrasts in the façade. (Source: Authors)

\section{CORPUS}

The corpus to be studied was given to participants in the form of circa 60 photos (e.g., Figure 1, Figure 2 and Figure 3 ) taken by the authors, and the possibility to search for more examples of housing customization using means such as Google street viewer. This last resource was very helpful and fully used by students because it also allowed them to have the alterations mapped in the complex and identify patterns within streets. Participants could also compare the current situation with the original plan by searching into the Malagueira Shape Grammar website by Duarte (http://home.fa.utl.pt/ jduarte/malag/).

\section{INFERING RULES}

For the Malagueira transformation grammar the process of developing the grammar, after the acquisition of research data, was followed by the definition of an ontology of the architectural elements that have been altered by the inhabitants. These elements include: shape (openings, grids, sun screens, exterior walls) and color (openings and frames of openings), all indicated in Table 1. To every element that inhabitants have changed (removed or added) an assessment was done by the participants if it should be acceptable and if so how to include it in the transformation grammar.

When analyzing the corpus the two groups did several drawings of the existing customization cases to get a feeling of them and to obtain, through drawing, a pattern of alterations (Figure 5).

Table 1 - Elements that were subject to alterations by inhabitants
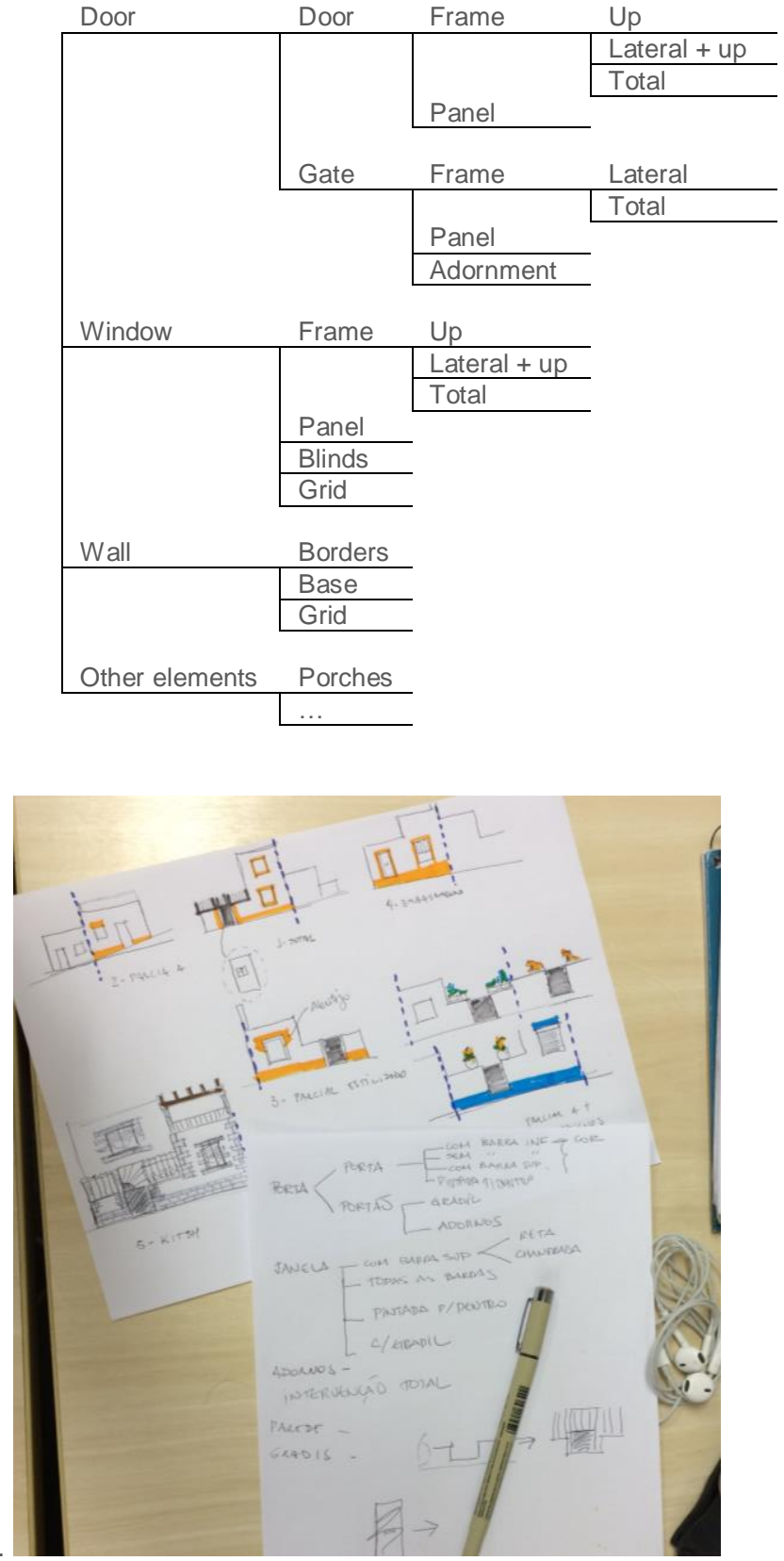

Figure 5: Analysis of the corpus and categorization of the existing alterations to Malagueira houses (Drawings by Daniel Athias and Marcelo Sbarra)

These architectonic elements where changed in their shape and the coating used for the façade walls. 
Regarding shape the alterations were inferred and translated to the transformation grammar as will be explained in the next section. Alterations in the façade coating were done using painted plaster (blue, yellow, grey and red in different tones), stone and ceramic.

Including in a transformation grammar the wishes of the inhabitants raises the issue of deciding if all the solutions by inhabitants are admissible from an architectural perspective. Participants and tutors of the workshop discussed that topic during the exercise. It was clear that participants considered the problem when one group categorized the alterations in four categories: partial, partial stylized, partial plus adornments, and kitsch. This last category, kitsch, was created to include the alterations that were considered not to follow architectural practices and therefore not to be considered as an admissible alteration to be including in the grammar (Figure 5). The kitsch alterations included mainly houses that had customized extensively all the elements identified. One of the outmost examples of such customization is shown in Figure 1 where the inhabitants built two porches, a new staircase, grids on the wall, ceramic frame with a "steps" design applied to the windows and outside wall.

\section{GRAMMAR RULES}

Both group 1 and group 2 developed a set of rules that can be applied to the original design of the houses. The grammar rules here presented are inspired by the work of the two groups and further developed by the authors to meet the shape grammar formalism including the necessary conditions for applying the rules. The strategy required to alter the façades of the original houses involves work on the walls, windows, doors and gates. All the transformations considered involve adding frames, adding metal grids, and adding colours. The proposed rules therefore include the following types of rules which should be applied in the given sequence:

1. Shape rules for Windows (SWi)

2. Shape rules for Doors (SD)

3. Shape rules for Gates (SG)

4. Shape rules for Walls (SWa)

5. Colour rules $(\mathrm{C})$

Erro! Fonte de referência não encontrada. shows a simplification of rules that includes the shape part and the condition part. In this grammar when a rule is applied it must be applied simultaneously to all the elements of the same type. E.g., if rule SWi2 is applied to a window it must be applied to all the windows of the house. This principle stands for:

- The chosen rule SWi must be applied to all the windows of the house;

- $\quad$ The chosen rule SD must be applied to all the doors of the house;

- The chosen rule $\mathrm{C}$ must be applied to all the elements (door, window, wall) of the house.

The proposed grammar is defined in the algebra U12, in which lines are combined on a plane and U22, in which surfaces are combined on a plane, both supporting the facade definition. The condition part, which is included in the shape rule, is essential to ensure that its use is limited to particular cases. The conditions are divided into dimensional and colour state conditions. The former includes linear dimensions (high and length) of elements and the latter an indication of the colour state of the elements referred to in the rule.


SG2

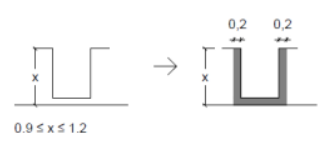

SG3

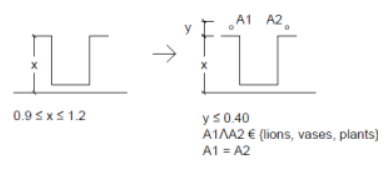

swi
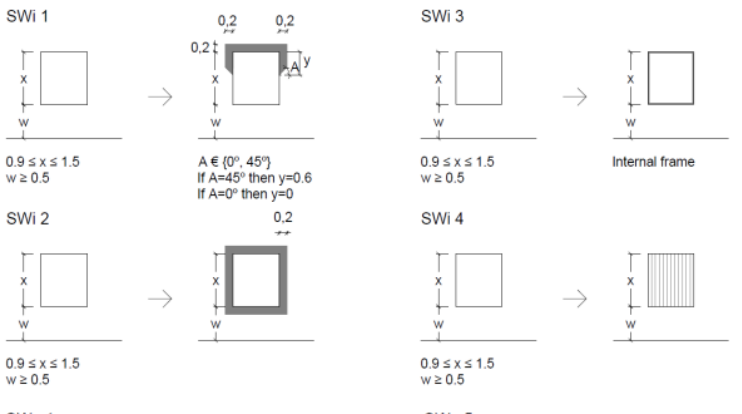

SWi 4

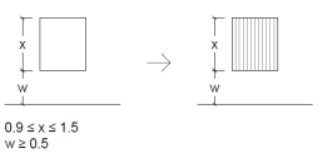

SWa 1

SWa 5

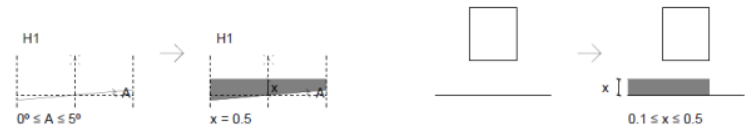

swa
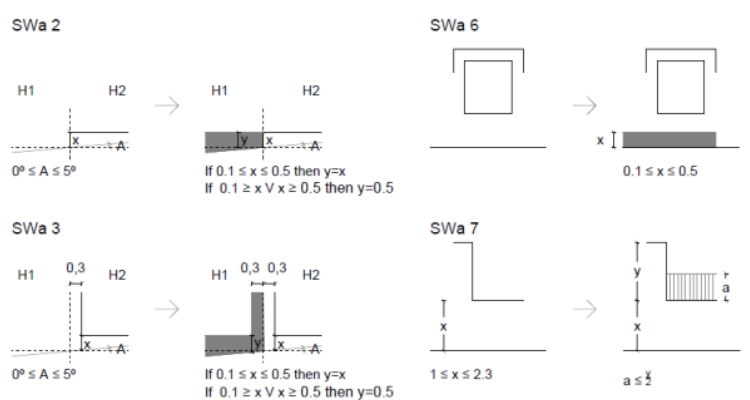

SWa 3

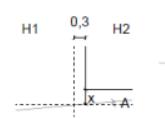

$0^{\circ} \leq \mathrm{A} \leq 5^{\circ}$

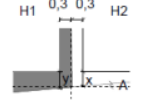

If $0.1 \leq x \leq 0.5$ then $y=x$
If $0.1 \geq x V x \geq 0.5$ then $y=0.5$

$a \leq \frac{1}{2}$

SWa 4
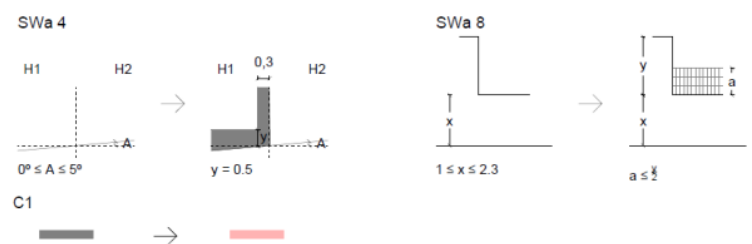

$c 2$

C3

$\mathrm{C} 4$

Figure 6: Shape grammar rules for the proposed

Transformation Grammar of Malagueira. Source: Authors. 
Group 2, Marília Chaves Lima, defined a grammar to "fix" the existing situation. Therefore, her approach was to transform the current state of the houses. Different rules were introduced for this. Figure 7 shows schematic rules for windows that are to be applied both to the current state of windows (if they have been altered) and to the original ones. In this set of rules, e.g., if there is a window that was altered to, say be painted white, the rule indicates that the window should be painted in one of the proposed colors. For such a case of a post-handover transformation grammar given so many years after that the houses were built, it would be beneficial to guide inhabitants in what current customizations they could maintain, and which should be changed and how.



Figure 7: Schematic shape rules for fixing alterations done by inhabitants (Adapted from the work of Marília Chaves Lima)

\section{DERIVATIONS AND FUTURE WORK ON THE GRAMMAR}

The application of the developed grammar enables to generate street façades that are closer to what exist nowadays by the customization done by inhabitants. Figure 8 shows several houses customized in two street layouts, one flat street and one slope street. In these solutions the overall volume of the buildings is maintained and, although new colorful frames are included, those volumes still excel in the building mass. The customization enabled by the grammar allows to differentiate houses which guarantees the individualization of property as well as the assurance of the feeling of identity among inhabitants.

The presented grammar is a first attempt that, to fulfil the aim of the study, would need to be discussed with the inhabitants and refined considering issues as:

- Should customization be restricted to maintain some homogeneity in the complex?

- Should the homogeneity be considered in a street or should it be considered in the whole complex?

- Should more customization be allowed?

The grammar defined included most of the customizations identified when analysing the current state of the Malagueira houses. Although there was a slight reduction compared to the existing alterations, the grammar applied produces an extensive alteration to the original design and therefore its use would have to be discussed with all the stakeholders involved as we will argue in the last section of this paper. In this line of thinking the option of including more restrictions on the alterations of the original design would be a possibility. A different line of thinking would be the option of including even more possibilities for alteration of the façades. In the transformation grammar defined solutions like stone and ceramic frames were not included (see Figure 1 and Figure 2). Also the construction of porches and metal stairs (Figure 1) were neglected as they significantly alter the building volume and have therefore a much higher impact on the original design. The grammar also does not consider any alteration of the interior layout since that was not the goal of this research.

Some eventually less popular solutions were identified in the developed rules. Rules SWa defines the base frame that can be introduced in the houses. For aesthetic reasons it was defined that the base frame would not stop
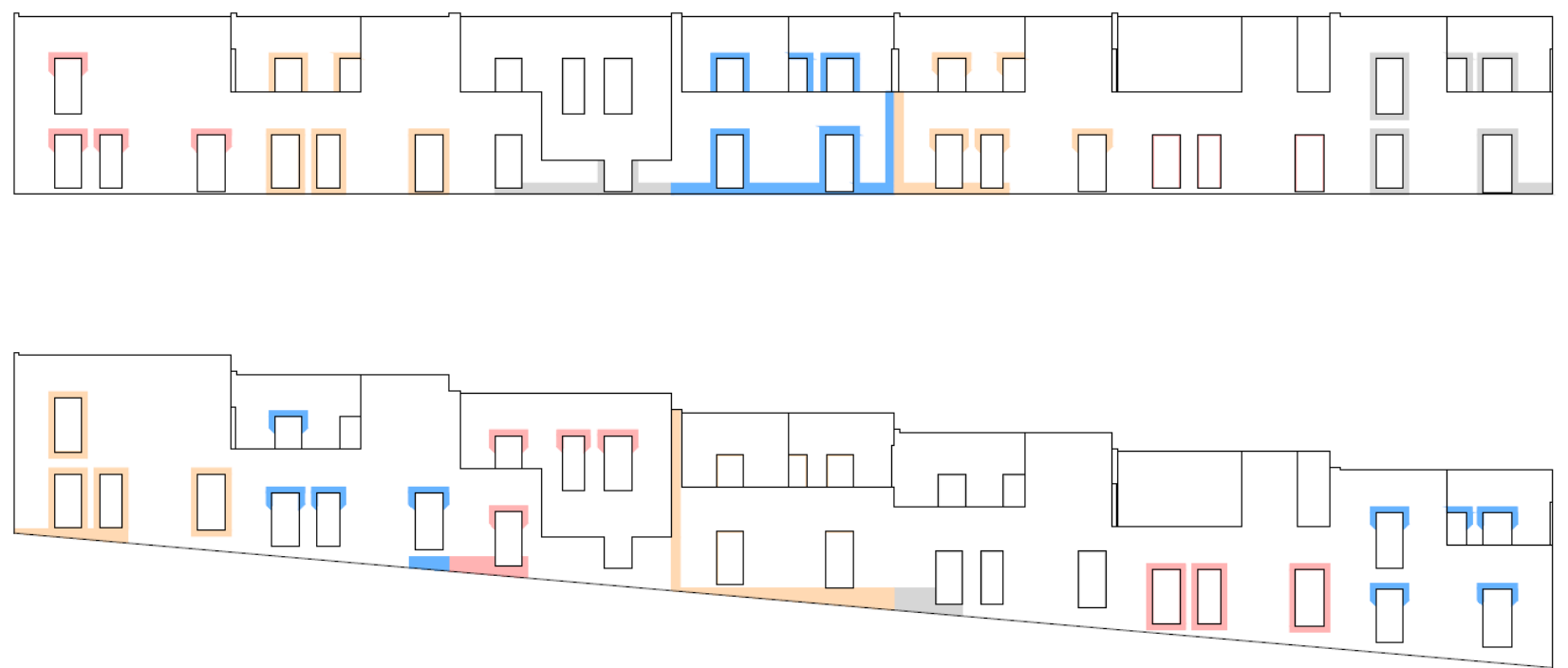

Figure 8: Derivations showing the application of Malagueira transformation grammar rules to one possible street façade. Source: Authors. 
horizontally at the end of the house. Instead, the developed rules include solutions that require the alignment of this base frame with other architectonic elements: doing a vertical border aligned with the end of the house (SWa3 and SWa4), stopping the horizontal line in the alignment of the closer window or door (SWa5 and SWa6, Figure 9 middle). Although there is an aesthetic reason for such a composition, this last solution would probably create a disagreement with the inhabitants because from the outside the property seems smaller than it actually is.
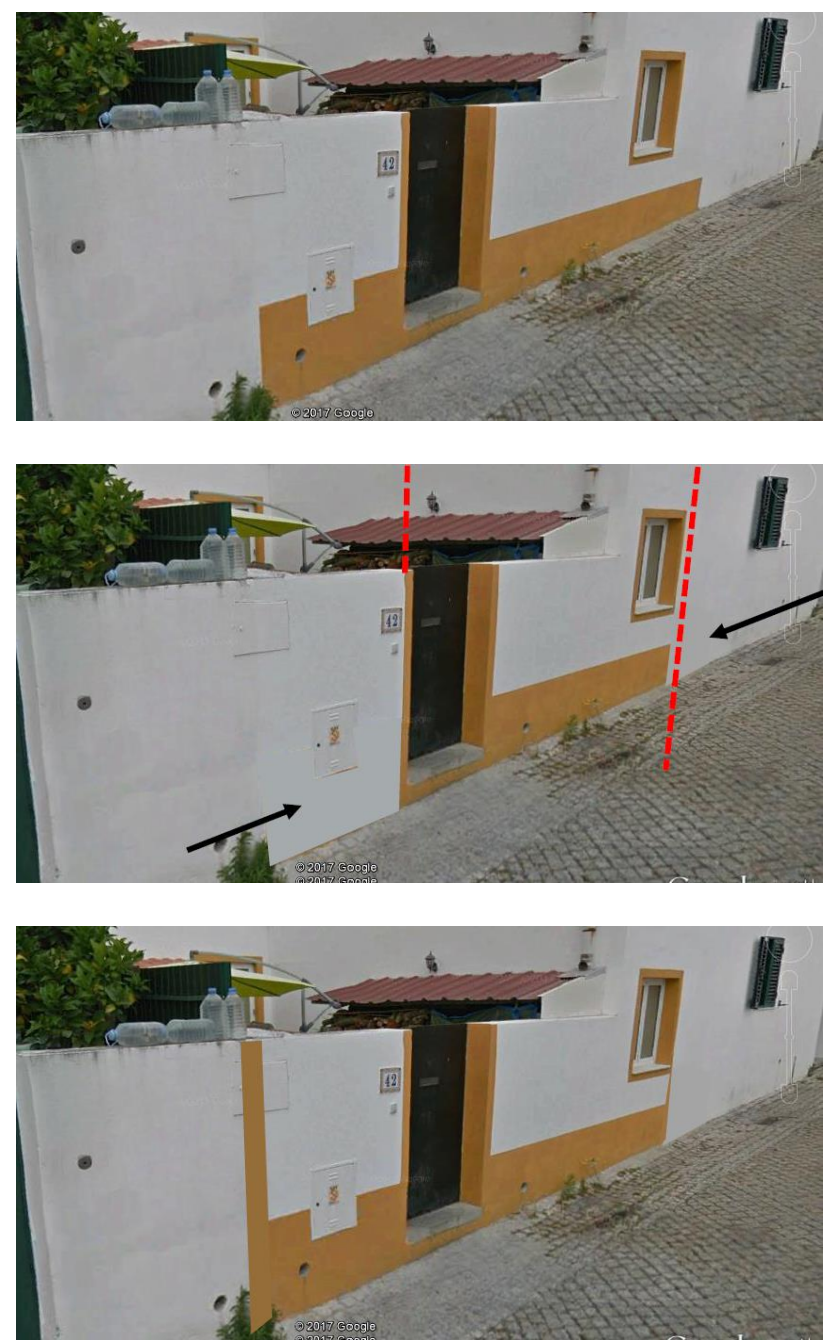

Figure 9: Top, original solutions for the base frame; middle and down, proposed solutions for the base frame (Adapted from the work of Marília Chaves Lima)

\section{DISCUSSION AND CONCLUSION}

In this research we described the development of transformation grammars for façade customization of housing in the Malagueira complex in Évora, Portugal, by Siza Vieira. These transformation grammars capture alterations that inhabitants of Malagueira have made to their houses after the handover of their houses; we therefore call the developed grammars post-handover shape grammars. The exercise described in this paper led to the development of a design strategy that empowers inhabitants with a tool that gives them freedom to perform alterations on their houses without compromising the architectural quality of the buildings.
Three advantages of such post-handover shape grammars can be named. First, they enable inhabitants to customize their houses when they are living in them. And Malard et al (2002) have shown how the participation of the users in an evaluation and co-design process done in the post-construction phase increases their satisfaction and well-being. Second, they are means to adjust housing to evolving demands, say to the changing circumstances of inhabitants or to new regulation. For instance, the Rabo-de-bacalhau transformation grammar by Eloy (Eloy \& Duarte, 2015) allows inhabitants to update the layout of their housing to new functional demands that emerge from new composition of the household and from new life styles. Third, with post-handover grammars inhabitants can improve the quality of their housing.

Taking a step outside the focus of this research: residents in slums, generally solve their housing needs without any support from government authorities. Such informality for solving both the design and the construction parts is a slum characteristic and is rarely part of architects and urban planners' studies in their professional routine. Seeking to recognize patterns in the slums housing layout and urban design, the research group Teaching Observation of UFRJ have been developing a study on the application of the Shape Grammar methodology to the favela of Rocinha (Dias, Gani, \& Chokyu, 2013). Rocinha has officially 143,72 ha with a population of almost 69.500 habitants and the quality of life offered is notoriously low. The grammar under development starts by an analytical grammar identifying the encountered informally-designed solutions and aims at evolving to a transformation grammar with which surgical interventions can be performed in the houses guarantying a higher quality of life, namely creating natural light and ventilation.

A disadvantage of the grammars developed at the workshop is that, although created in the tradition of participatory design, they cannot be taken as such. They tried to capture the wishes of inhabitants and incorporate them in the architecture through shape grammars. But it does so primarily by architects. A next step would be to do the workshop with inhabitants of Malagueira.

A more general issue is the relation of this approach to Siza Vieira as the original author as architect of Malagueira. One could argue that post-handover shape grammars find a balance between the additions that inhabitants make to their housing and the original architecture by capturing the architectural language of the housing; the customization that the shape grammars presented here allow leave the architectural coherence of Malagueira undamaged. Clearly, Siza Vieira can disagree. And clearly architects may rebut that it should be they how are determining possible customization, rather than efforts that are undertaking independently of them. Some architects indeed do give rules for this during the designing of new housing. House maker by MVRDV (MVRDV \& Axis.fm, 2012), for instance, avoid the conflict with users by immediately giving rules that could be composed by users to create their house. Also, Siza Vieira has offered similar possibilities by designing Malagueira with an incremental design allowing that inhabitants could increase the houses by adding extra rooms. However one can applaud such pre-handover developed tools for customization, the conflict will remain to exist: after handover inhabitants still may want to make 
changes beyond what is enabled by these tools. Hence, responses to post-handover customization remain needed, and post-handover grammars such as the one we presented here may be such a response in which an architectural balance is struck between the additions that inhabitants make and the original architecture of their housing.

\section{ACKNOWLEDGMENTS}

We thank all the participants in the Rio de Janeiro Workshop and specially Marilia Chaves Lima, Daniel Athias and Marcelo Sbarra whose work is part of this paper. We would also like to thank Guida Ramos for the redrawing of all the rules. We also like to thank Fundação para a Ciência e Tecnologia through project ISTAR UID/MULTI/4466/2016.

\section{REFERENCES}

Bosma, K., Hoogstraten, D. van, \& Vos, M. (2000). Housing for the Millions: John Habraken and the SAR (1960-2000). Rotterdam: NIA Publishers.

Coimbra, E., \& Romão, L. (2013). The Rehabilitation Design Process of the Bourgeois House of Oporto: Shape Grammar Simplification. In eCAADe 2013 Computation and Performance (Vol. 2, pp. 677-686). Delft (The Netherlands).

Colakoglu, B. (2005). Design by grammar: An interpretation and generation of vernacular hayat houses in contemporary context. Environment and Planning B: Planning and Design, 32(1), 141-149. https://doi.org/10.1068/b3096

Dias, M. Â., Gani, D., \& Chokyu, M. (2013). A lógica da favela pela gramática da forma. Arq.Urb, 10, 23-40.

Duarte, J. P. (2005). Towards the mass customization of housing The grammar Siza's houses at Malagueira. Environment and Planning B: Planning and Design, 32(3), 347-380. https://doi.org/10.1068/b31124

Eloy, S. (2014). Rabo-de-Bacalhau building type morphology: data to a transformation grammar-based methodology for housing rehabilitation. Arq.Urb - Revista Eletrônica de Arquitetura e Urbanismo. Retrieved from http://www.usjt.br/arq.urb/numero-11/4-sara-eloy.pdf

Eloy, S., \& Duarte, J. P. (2015). A transformation-grammar-based methodology for the adaptation of existing housetypes: the case of the 'rabo-de-bacalhau.' Environment and Planning $B$ : Planning and Design, 42(5), 775-800. https://doi.org/10.1068/b120018p

Gomes, M. (2016). Factores de apropriação e construção identitária em torno da casa. Estudo de Caso - Bairro da Malagueira de Siza Vieira. Universidade Nova de Lisboa.
Habraken, N. J. (1972). Supports: an alternative to mass housing. London (UK): The Architectural Press.

Kendall, S., \& Teicher, J. (2000). Residential Open Building. London: E \& FN Spon.

Knight, T. (1989). Transformations of De Stijl art: the paitings of Georges Vantongerloo and Fritz Glarner. Environment and Planning B: Planning and Design, 16(1), 168-217. https://doi.org/10.1068/b160051

Knight, T. (2015). Regarding Rules: From Rimini to Rio. Joelho, 13-27.

Malard, M. L., Baltazar, A. P., Pontes, M. M., \& Fialho, P. H. (2006). Possibilidades projetuais para experimentações de componentes e sistemas construtivos: a noção de "projeto aberto." In XI Encontro Nacional de Tecnologia do Ambiente Construído (pp. 3205-3214). Florianópolis. Retrieved from http://www.infohab.org.br/entac2014/2006/artigos/ENTAC200 6_3205_3214.pdf

Malard, M. L., Conti, A., Souza, C. F. de, \& Campomori, M. J. L. (2002). Avaliação pós-ocupação, participação de usuários e melhoria de qualidade de projetos habitacionais: uma abordagem fenomenológica. In A. K. Abiko \& S. W. Ornstein (Eds.), Inserção Urbana e avaliação pósocupação(APO) da habitação de interesse social. (Vol. 1, pp. 242-267). São Paulo: Coleção Habitare.

McKay, G. (2016). Le Corbusier Algiers. Modest Megastructures. Retrieved December 22, 2016, from https://misfitsarchitecture.com/tag/le-corbusier-algiers/

MVRDV, \& Axis.fm. (2012). Architecture in Mind. The HouseMaker. In MVRDV \& The Why Factory (Eds.), The Vertical Village. Individual, Informal, Intense (pp. 169-194). NAi Publishers.

Rodrigues, A. L. (2015). A experiência da Quinta da Malagueira (1977): Ensinamentos e cautelas na concretização de habitação de custos-controlados, para uma arquitetura avisada. In $3^{\circ} \mathrm{CIHEL} \mathrm{-} \mathrm{congresso} \mathrm{Internacional} \mathrm{de} \mathrm{Habitação}$ no Espaço Lusófono (pp. 1-14). São Paulo (Brasil).

Sanoff, H. (2008). Multiple Views of Participatory Design. International Journal of Architectural Research, 23(1), 131143. https://doi.org/10.15368/focus.2011v8n1.1

Stiny, G. (1980). Kindergarten grammars: designing with Froebel's building gifts. Environment and Planning $B$ : Planning and Design, 7, 409-462.

Stiny, G., \& Gips, J. (1972). Shape Grammars and the Generative Specification of Painting and Sculpture. In O. Petrocelli (Ed.), The Best Computer Papers of 1971. New Jersey: Auerbach. 